\title{
Emergency Communication and Quick Seismic Damage Investigation Based on Smartphone
}

\author{
Ruicong Han, ${ }^{1,2}$ Xuefeng Zhao, ${ }^{1,2}$ Yan Yu, ${ }^{3}$ Quanhua Guan, ${ }^{4}$ Deli Peng, \\ Mingchu $\mathrm{Li}^{4}{ }^{4}$ and Jinping $\mathrm{Ou}^{1,2,5}$ \\ ${ }^{1}$ School of Civil Engineering, Dalian University of Technology, Dalian 116024, China \\ ${ }^{2}$ State Key Laboratory of Coastal and Offshore Engineering, Dalian University of Technology, Dalian 116024, China \\ ${ }^{3}$ School of Electronic Science and Technique, Dalian University of Technology, Dalian 116000, China \\ ${ }^{4}$ School of Software Technology, Dalian University of Technology, Dalian 116000, China \\ ${ }^{5}$ School of Civil Engineering, Harbin Institute of Technology, Harbin 150000, China
}

Correspondence should be addressed to Xuefeng Zhao; zhaoxf@dlut.edu.cn

Received 8 April 2016; Revised 31 May 2016; Accepted 20 June 2016

Academic Editor: Francesco dell'Isola

Copyright (C) 2016 Ruicong Han et al. This is an open access article distributed under the Creative Commons Attribution License, which permits unrestricted use, distribution, and reproduction in any medium, provided the original work is properly cited.

\begin{abstract}
The communications in the quake-hit area are always cut off from the outside after the earthquake, and the traditional seismic field investigation method calls for immense time to accomplish house-to-house investigation, which goes against timeliness of the emergency rescue. In this paper, an emergency communication and quick seismic damage investigation method based on smartphone is proposed. Towards this, an application, E-Explorer, on iOS platform is initially developed. First, in the emergency communication module, the communication is available by using the Multipeer Connectivity Framework technology even without external network. A series of validation experiments are simulated without external network, and the results prove convincing. This module enhances the possibility of communication and increases the chances for rescue. Second, in the damage investigation module, E-Explorer integrates the functions of questionnaire and picture collection for damage phenomenon recording and image acquisition, following an intensity evaluation method according to seismic index. Last, a website, which provides guidance for rescue workers and collects damage information for quick intensity evaluation, is being built.
\end{abstract}

\section{Introduction}

The immediate resilience after the earthquake is becoming an important aspect worth being investigated [1,2]. Emergency relief is the top priority. According to the Japan Kobe earthquake statistics, after the earthquake, $60 \%$ of buried people died shortly, while $40 \%$ of buried people are still alive and waiting for rescue [3]. A critical component of any successful rescue operation is time. However, the whole disaster areas are always cut off from the outside due to traffic congestion and communication interruption; the disaster rescue team cannot rush to the disaster area in a short time. So the direct involvement of residents is extremely important during the emergency, because it can improve the response and rescue process [4-9]. Thus, after the earthquake, residents in disaster areas actively and efficiently involved in mutual aid in the earthquake zone are the most effective means to reduce casualties [10]. Our method can realize communication even without an external network, which will help officers get in touch with the trapped human which will be significant for saving lives.

The rapid assessment of losses at the first time after an earthquake can help officers determine the disaster affected areas and then provide scientific guidance for emergency response and rescue, which is significant to reduce casualties. However, the traditional damage investigation method after the earthquake needs multiple field investigation; the firsthand seismic disaster information cannot be mastered by the government. Moreover, the intensity values obtained by different investigators in one survey point may be different, which leads to great uncertainty in damage assessment. In fact, residents may help to identify an emergency and they can 
play a significant role in the damage investigation progress. A higher number of residents will allow experts to better allocate government resources where they are needed and supplement the limited resources, helping them to go further [11]. So, a quick damage investigation method which can motivate residents is necessary.

Implementation of new information technologies in emergency response can potentially improve communication and coordination $[12,13]$. Smartphones as a mobile-based information technology can be a solution to benefit quick seismic damage investigation and emergency communication in postdisaster relief experience. With an operating system, communication system, and built-in sensors, they have already been used in many fields other than the communication field, including human health monitoring [14], vehicle accident detection [15], motivation recognition [16], seismic sensing [17], and structural health monitoring [18-25]. What is more, smartphones and the Internet provide a means to use after an earthquake when a response is needed, especially since individuals are becoming very comfortable with the use of smartphones. Smartphones facilitate response in largescale emergencies by enabling individuals to report information. Few examples of these applications are given by researchers [26-28], who developed a system for building damage assessment. However, their proposed application is only available in the Android operating system, which is a drastic limitation for the residents. Cimellaro et al. [29] developed an application, EDAM, on iOS and Android operating systems to survey the building earthquake damage, which is a perfect investigation system. But the emergency communication without external network is not considered, which is significant for saving lives. Fortunately, with the assistance of Wi-Fi hotspot and Bluetooth of various operating systems, smartphones can realize communication even without external networks.

In this paper, a new emergency response system based on smartphones is proposed. Towards this, the software EExplorer which initially focused on the iOS operating system was developed with two main modules. First, the emergency communication is proposed by using Multipeer Connectivity Framework technology even without any external network. A series of experiments including connection experiment, connection distance experiment, and information transmission experiment were conducted to validate the feasibility of emergency communication under real conditions. Second, the quick seismic damage investigation is proposed to obtain first damage information right after the earthquake rapidly and efficiently by using smartphones which assist both specialists and residents to collect information about the disaster, following an intensity evaluation method based on seismic damage index according to Chinese Seismic Intensity Scale (2008). Last, a website (http://www.e-explorer.cn/) is built to gather disaster big data. On the one hand, trapped people's security status and positions are presented on the website to provide guidance for life relief, and, on the other hand, the damage pictures and questionnaire are integrated for intensity evaluation.
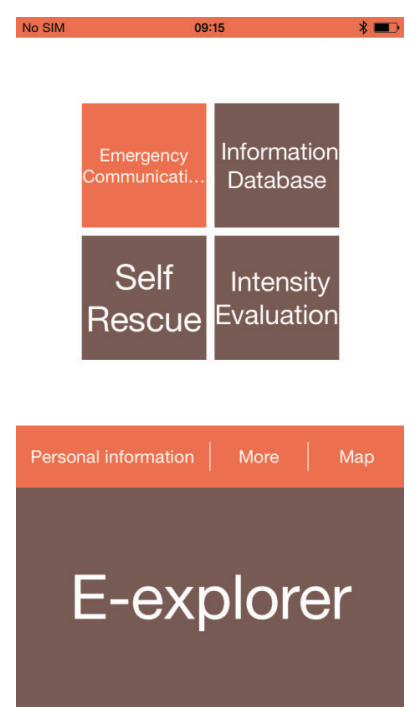

FIGURE 1: Main interface of E-Explorer.

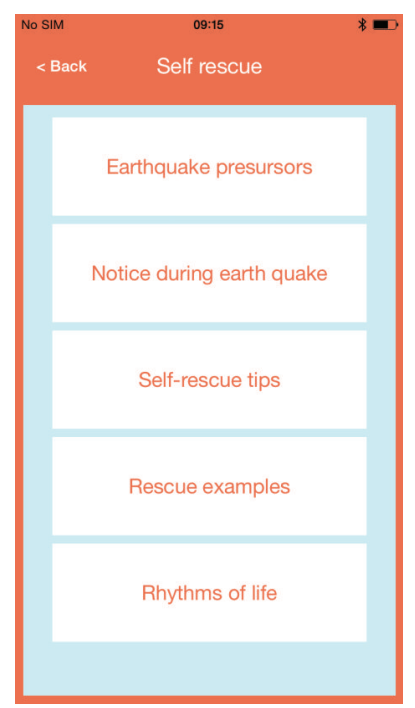

FIGURE 2: Self-rescue knowledge after earthquake.

\section{E-Explorer Overview}

E-Explorer has been uploaded to Apple App Store for free download. And the Android version is being developed. The main interface is shown in Figure 1; two main modules, emergency communication and intensity evaluation, are developed. Emergency communication makes the information transmission possible even without an external network. Intensity evaluation is used to collect damage information by using questionnaire and pictures.

Emergency communication and intensity evaluation will be introduced in detail in the following parts. Except for these two modules, self-rescue is also developed in E-Explorer, which is shown in Figure 2. In this module, some general 
TABLE 1: Wi-Fi standard and Bluetooth of each type.

\begin{tabular}{lcc}
\hline iPhone type & Wi-Fi standard & Bluetooth \\
\hline iPhone $4 \mathrm{~s}$ & IEEE $802.11 \mathrm{~b} / \mathrm{g} / \mathrm{n}$ & Bluetooth 4.0 \\
iPhone 5 & IEEE $802.11 \mathrm{a} / \mathrm{b} / \mathrm{g} / \mathrm{n}$ & Bluetooth 4.0 \\
iPhone $5 \mathrm{c}$ & IEEE $802.11 \mathrm{a} / \mathrm{b} / \mathrm{g} / \mathrm{n}$ & Bluetooth 4.0 \\
iPhone $5 \mathrm{~s}$ & IEEE $802.11 \mathrm{a} / \mathrm{b} / \mathrm{g} / \mathrm{n}$ & Bluetooth 4.0 \\
iPhone 6 & IEEE $802.11 \mathrm{a} / \mathrm{b} / \mathrm{g} / \mathrm{n} / \mathrm{ac}$ & Bluetooth 4.2 \\
iPhone 6 Plus & IEEE $802.11 \mathrm{a} / \mathrm{b} / \mathrm{g} / \mathrm{n} / \mathrm{ac}$ & Bluetooth 4.2 \\
iPhone 6s & IEEE $802.11 \mathrm{a} / \mathrm{b} / \mathrm{g} / \mathrm{n} / \mathrm{ac}$, MIMO & Bluetooth 4.2 \\
iPhone 6s Plus & IEEE $802.11 \mathrm{a} / \mathrm{b} / \mathrm{g} / \mathrm{n} / \mathrm{ac}$, MIMO & Bluetooth 4.2 \\
iPhone SE & IEEE $802.11 \mathrm{a} / \mathrm{b} / \mathrm{g} / \mathrm{n} / \mathrm{ac}$, MIMO & Bluetooth 4.2 \\
\hline
\end{tabular}

knowledge during or after earthquake is provided to save selflives; also, some rescue examples are provided to increase the confidence of being rescued.

\section{Emergency Communication without External Network}

3.1. Communication Principle. The communication is based on Multipeer Connectivity, which is a framework that enables nearby devices to communicate over infrastructure Wi-Fi networks, peer-to-peer $\mathrm{Wi}-\mathrm{Fi}$, and Bluetooth personal area networks [30].

When the external network is available, E-Explorer can, as a general application, communicate with other devices freely. Otherwise, Wi-Fi hotspot or Bluetooth is selected to communicate with nearby devices according to the actual situation. The coverage radius of the Bluetooth is within $15 \mathrm{~m}$, which is not enough for communication. However, once the WLAN is open even without Wi-Fi connection, the smartphone can serve as a Wi-Fi wireless hotspot to connect with the nearby devices according to the Wi-Fi standard, which will promote the communication range greatly. The connectivity properties of different devices are different because of the configuration. Table 1 shows the Bluetooth type and the Wi-Fi standard of iPhone [31].

IEEEE 802.11 is the standard of the wireless local network. The characteristics such as bandwidth, transmission rate, and coverage radius of the protocol in iPhone are shown in Table 2 [32]. The physical tests about transmission distance in real conditions are conducted as Section 3.3.2 shows.

3.2. Emergency Communication after Earthquake. As Section 3.1 introduced, E-Explorer allows two mobile devices to exchange text and other formal information at a distance without external network connection. It may be an effective tool for emergency communication in the quake-hit area.

Figure 3 shows the realization flow chart of emergency communication. In E-Explorer, a database is built to store the important information for users under the special disaster background, including name, personal ID, position, whether they are trapped, injury status, and also the information notes of nearby people who call for help. The information needs to be filled and confirmed and then saved to the database. EExplorer allows two nearby smartphones to share respective information in the database automatically. Then, the important help information can be shared among the affected residents in this way theoretically. With more broad information sharing, more and more residents will get the information of trapped survivors. The information can be uploaded to the website as well, so that the relief rescue work can be implemented more efficiently with specific goals.

\subsection{Validation Experiments on Emergency Communication}

3.3.1. Connection Experiment. Firstly, we conducted a connection test to check the communication without external network. Six residents, A, B, C, D, E, and F, were equipped with smartphones without any external network. Their positions and iPhone version are shown in Figure 4; the maximum distance between two residents is $20 \mathrm{~m}$. Their personal information inputting interfaces are shown in Figure 5. It can be seen that the six smartphones' networks are not available. No SIM card is inserted; Bluetooth is available and WLAN is open without Wi-Fi connection.

After personal information submission, the six people are connected successfully and their information is shared. Taking C's screenshot as an example, Figure 6(a) shows the nearby people, and Figures 6(b) and 6(c) show the database. The communication among A, B, C, D, E, and F can be built, and everyone's messages can be received. The group chat is shown in Figure 6(d). A conversation between two people can be built by selecting one person in the database as in Figure 6(a). If $\mathrm{E}$ is chosen, $\mathrm{C}$ and $\mathrm{E}$ can communicate with each other freely. The conversation screenshot between them is shown in Figure 6(e).

From this experiment, it can be concluded that the communication can be built even if the external network is not available, and the information database can be uploaded to the website. Above all, after a major disaster, emergency communication through E-Explorer is very important for increasing residents' confidence of the emergency information and in promoting rescue efficiency.

3.3.2. Connection Distance Experiment. As experiment 1 validated, the communication can be built even without external network. The theoretical connection distance is given in Tables 1 and 2 . The actual connection distance was tested by two iPhone $4 \mathrm{~s}$ devices and two iPhone 6 devices.

In this experiment, iPhone 6 and iPhone $4 \mathrm{~s}$ were tested indoors and outdoors, respectively. One person equipped with one smartphone stands close to the wall, while another person equipped with a smartphone moves away from the first person to connect the smartphone. The diagram is shown in Figure 7. Six groups of experiments are conducted; the solid line represents the notion that the smartphone can receive another smartphone's message, while the dotted line represents the notion that the smartphone cannot receive another smartphone's message.

Beyond the threshold value, which is defined as the maximum connection distance, a mobile phone cannot receive information from another one. The maximum connection distance and the penetrating walls capability tested are shown in Table 3. 
TABLE 2: Characteristics of the communication protocol used in iPhone.

\begin{tabular}{|c|c|c|c|c|c|}
\hline Protocol & Bandwidth (GHz) & $\begin{array}{c}\text { Standard transmission rate } \\
(\mathrm{Mbit} / \mathrm{s})\end{array}$ & $\begin{array}{l}\text { Max. transmission } \\
\text { rate }(\mathrm{Mbit} / \mathrm{s})\end{array}$ & Coverage radius (indoor) & $\begin{array}{l}\text { Coverage radius } \\
\text { (outdoor) }\end{array}$ \\
\hline 802.11a & $\begin{array}{c}5.15-5.35 / 5.47- \\
5.725 / 5.725-5.875\end{array}$ & 25 & 54 & $30 \mathrm{~m}$ & $45 \mathrm{~m}$ \\
\hline $802.11 \mathrm{~b}$ & $2.4-2.5$ & 6.5 & 11 & $30 \mathrm{~m}$ & $100 \mathrm{~m}$ \\
\hline $802.11 \mathrm{~g}$ & $2.4-2.5$ & 25 & 54 & $30 \mathrm{~m}$ & $100 \mathrm{~m}$ \\
\hline $802.11 \mathrm{n}$ & $2.4 \mathrm{GHz}$ or $5 \mathrm{GHz}$ & $300(20 \mathrm{MHz} * 4 \mathrm{MIMO})$ & $\begin{array}{c}600(40 \mathrm{MHz} * \\
4 \mathrm{MIMO})\end{array}$ & $70 \mathrm{~m}$ & $250 \mathrm{~m}$ \\
\hline $802.11 \mathrm{ac}$ & $5 \mathrm{GHz}$ & $\begin{array}{c}433,867(80 \mathrm{MHz}, \\
160 \mathrm{MHz})\end{array}$ & $\begin{array}{l}867,1730,3470,6930 \\
(8 \mathrm{MIMO}, 160 \mathrm{MHz})\end{array}$ & $35 \mathrm{~m}$ & \\
\hline
\end{tabular}

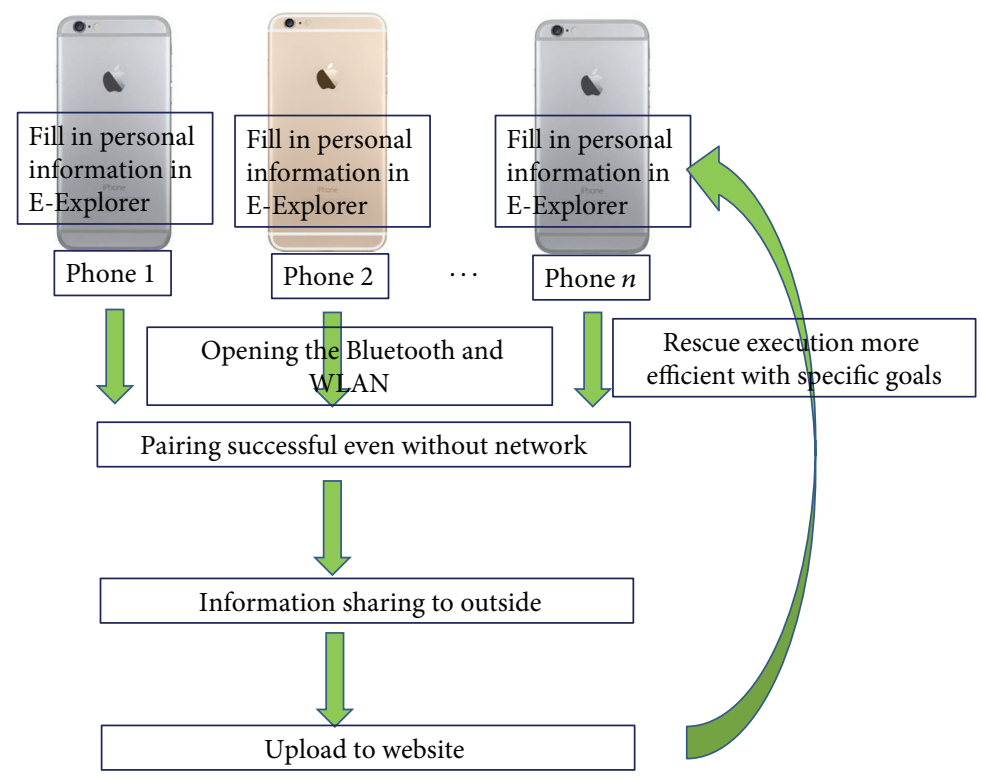

FIgURE 3: Emergency communication realization flow chart.

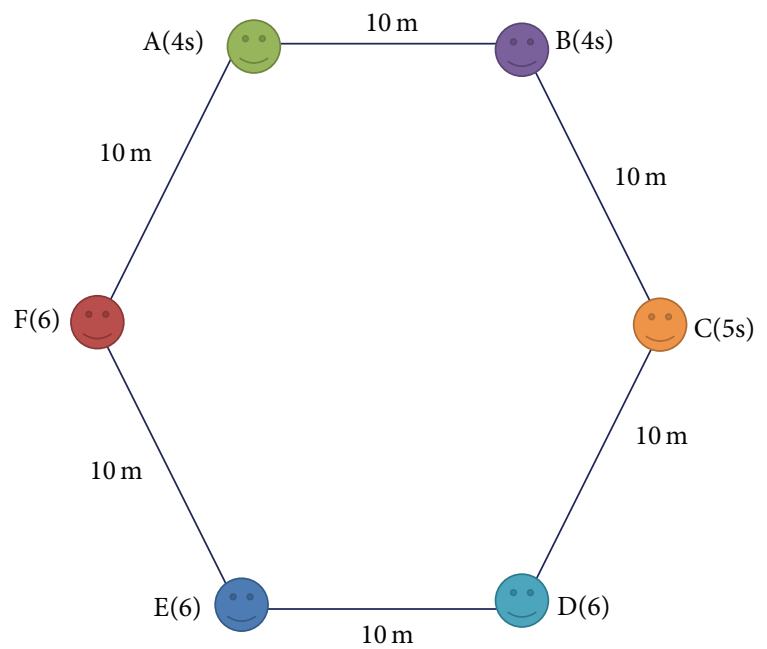

FIgURE 4: Positions and iPhone version of six residents.

From Table 3, it can be seen that the maximum distance outdoors is less than that indoors, which does not coincide with the theoretical transmission. This may be due to
TABLE 3: The tested maximum connection distance and throughwalls ability.

\begin{tabular}{lccc}
\hline Devices & $\begin{array}{c}\text { Indoor } \\
\text { maximum } \\
\text { distance }\end{array}$ & $\begin{array}{c}\text { Outdoor } \\
\text { maximum } \\
\text { distance }\end{array}$ & $\begin{array}{c}\text { Through } \\
\text { walls (load } \\
\text { bearing wall) }\end{array}$ \\
\hline $4 \mathrm{~s} \& 4 \mathrm{~s}$ & $45 \mathrm{~m}$ & $45 \mathrm{~m}$ & 1 \\
$6 \& 6$ & $70 \mathrm{~m}$ & $55 \mathrm{~m}$ & 1 \\
$4 \mathrm{~s} \& 6$ & $55 \mathrm{~m}$ & $50 \mathrm{~m}$ & 1 \\
\hline
\end{tabular}

the more serious signal disturbance outdoors compared with that indoors. The communication distance of a higher version smartphone is better than that of a lower version smartphone. In the practical tests, the connection rate of iPhone 6 is better than that of iPhone $4 \mathrm{~s}$ because of the bandwidth and transmission rate difference shown in Table 2 . The capability of penetrating walls is not so perfect. This may be a limit for trapped people, whose condition is very complex. In general, it is difficult to determine the actual communication range, and connection failure is most likely to occur in the hit-quit 


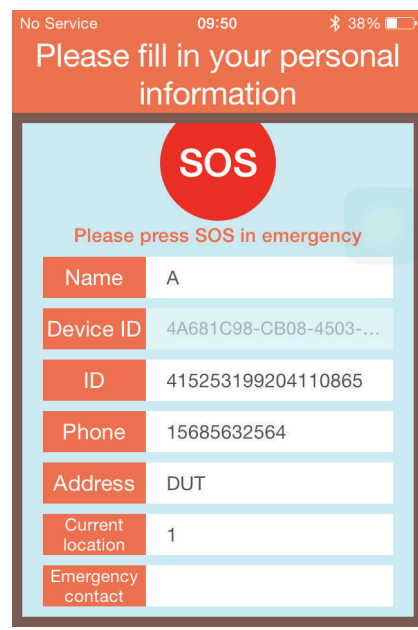

(a)

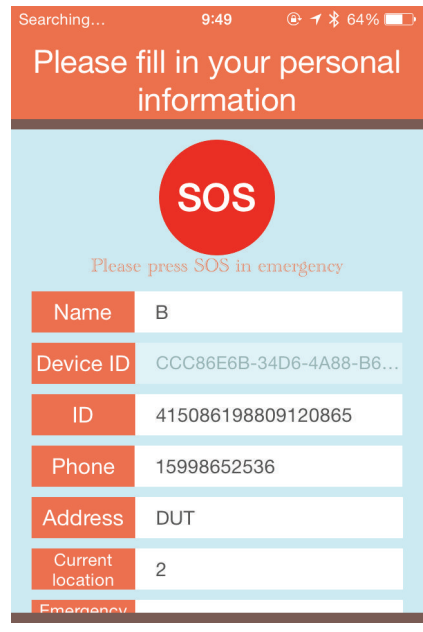

(b)

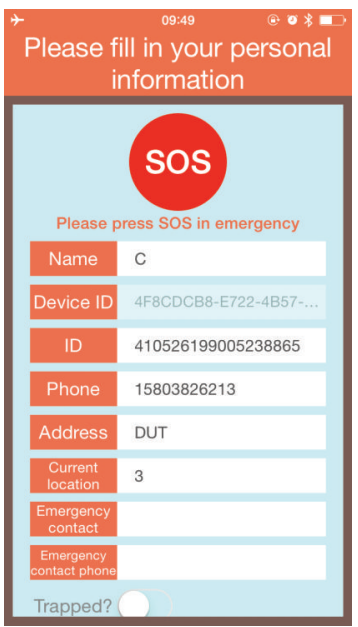

(c)

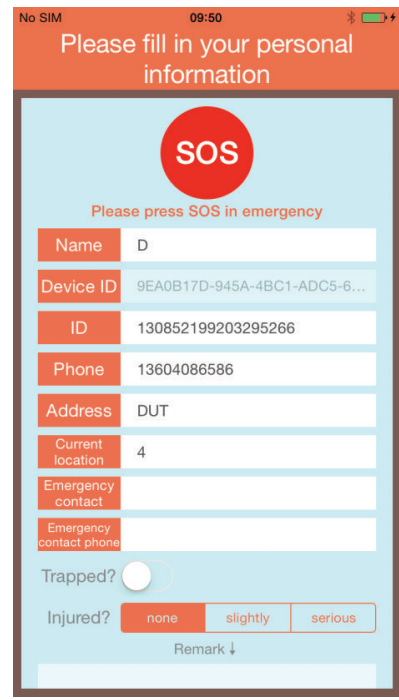

(d)

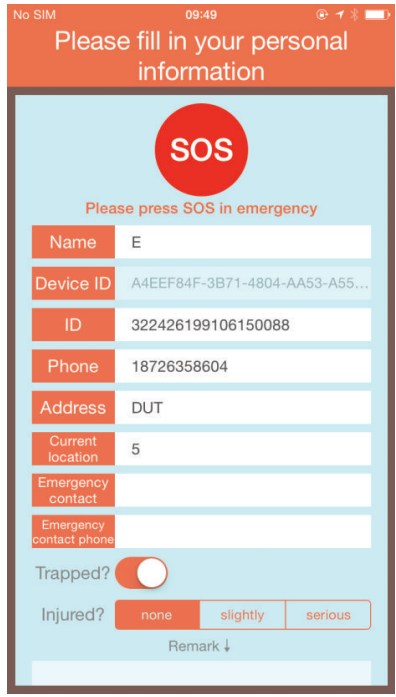

(e)

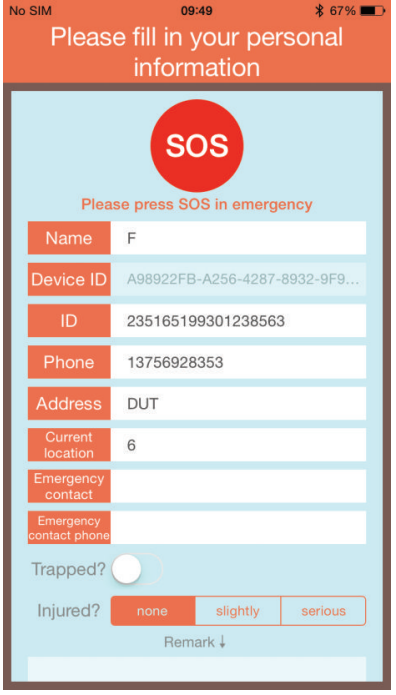

(f)

FIGURE 5: Inputting interfaces and networks.

area. But trapped people can call for help to nearby people who can communicate with the outside, and then the information can be delivered to the outside as a note on the nearby people's smartphones. This app offers more chances for disaster rescue and also provides the possibility of communicating with trapped people even when the external network is cut off.

3.3.3. Information Transmission Experiment. The experiments in Section 3.3.2 indicate that the connection distance is restricted; the connection of two smartphones may fail because of the large distance. So, information transmission is an issue to be considered. As Section 3.2 demonstrated, the connection node will contribute to information transmission. Two tests on different transmission patterns of smartphone node are given below.
(A) Moving Node Pattern. Figure 8 shows the experiment diagram. A, B, D, E, and F all opened up E-Explorer, and the distance between every two people is $80 \mathrm{~m}$. The external networks of tested smartphones are not available. They cannot connect to each other because of the large distance. $\mathrm{C}$ is a moving person with E-Explorer opened and walks from $\mathrm{A}$ to F.

Figure 9 shows the test results of moving node experiment, Figures 9(a) and 9(c) show the information database on E and F, and Figures 9(b) and 9(d) show the nearby people of $\mathrm{E}$ and $\mathrm{F}$. It can be seen that only two people can be connected; once C connected to one person, the information on C's smartphone can be shared. Consequently, the information of A-E can be transmitted to $\mathrm{F}$.

From this experiment, it can be concluded that even if the connection is not available because of the long distance, once 


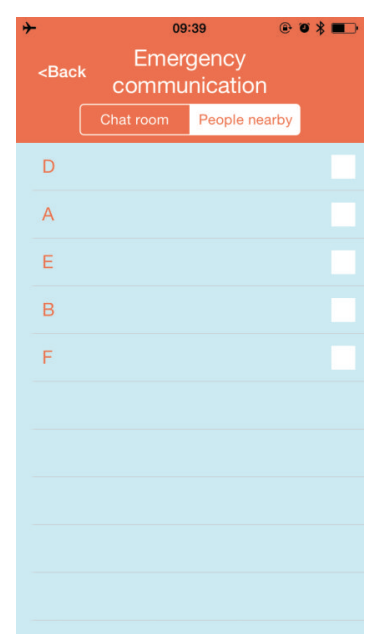

(a) Nearby people

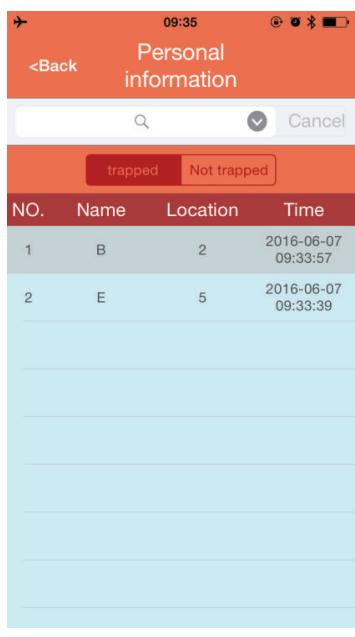

(b) Trapped people
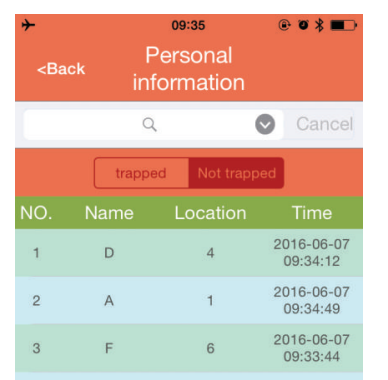

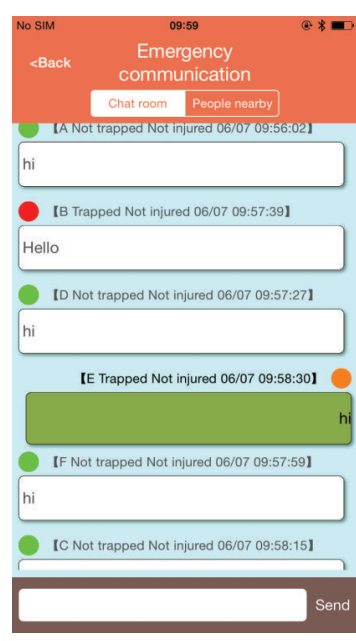

(d) Group chat

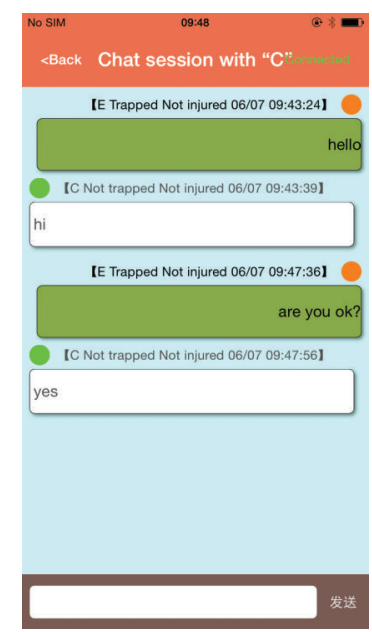

(e) Person-to-person chat

Figure 6: Information on C's smartphone.

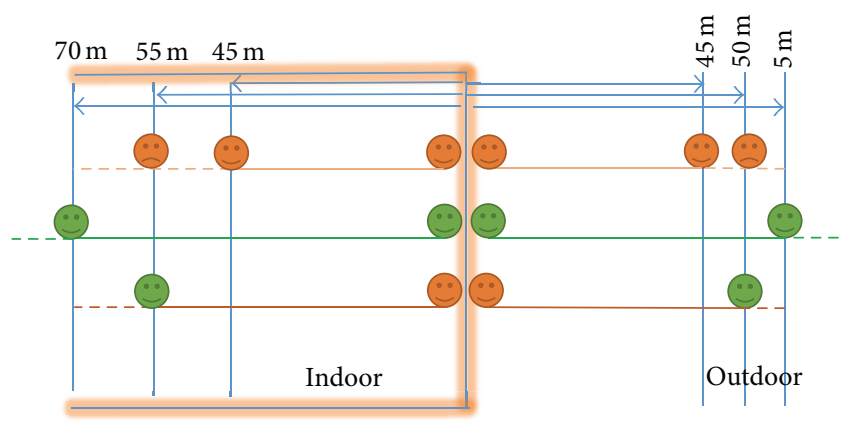

iPhone $4 \mathrm{~s}$

iPhone 6

Figure 7: Connection distance experiment diagram.

a moving node exists, a temporary connection can be built and the information will be shared. This contributes to the earthquake relief work; a person who is not trapped can be a node to transmit information to the outside.

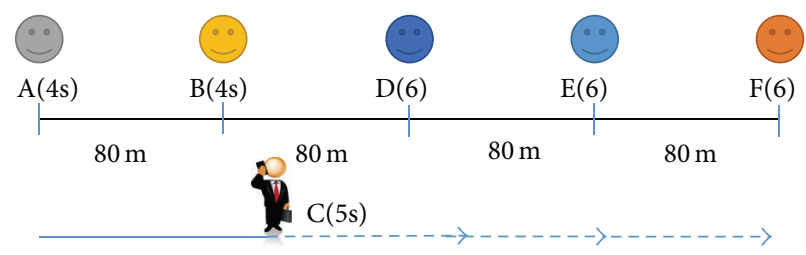

FIGURE 8: Moving node pattern experiment diagram.

(B) Dense Node Pattern. In order to build a distributed sensor network, a dense node experiment was conducted. The experiment diagram is shown in Figure 10. In the first step, A and $\mathrm{F}$ stand within a distance of $200 \mathrm{~m}$. In the second step, B and $\mathrm{C}$ are added between $\mathrm{A}$ and $\mathrm{F}$. Last, $\mathrm{D}$ and $\mathrm{E}$ are added between $\mathrm{C}$ and $\mathrm{F}$. Their positions are shown in Figure 10.

For the first step, A and F cannot be connected because of the large distance.

For the second step, the information on $\mathrm{C}$ is shown in Figure 11(a); it can be seen that the information of A and B can be shared to $\mathrm{C}$. 


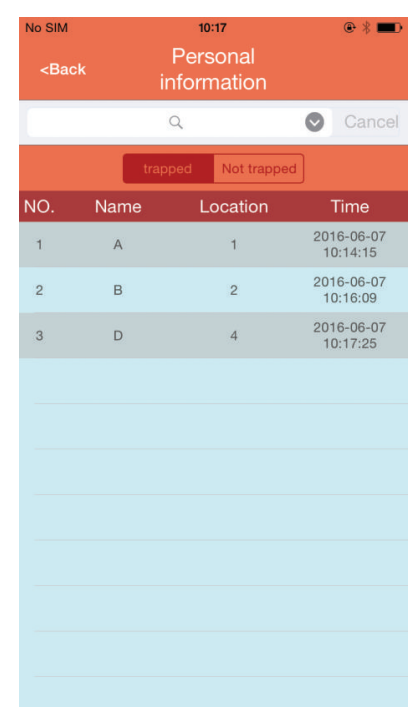

(a) Database on E's smartphone
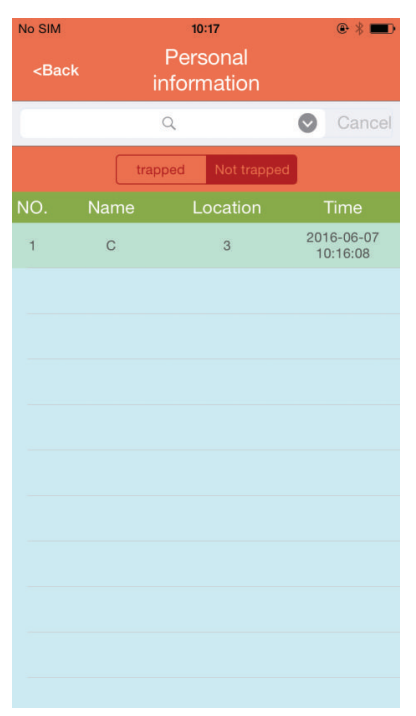

(b) E's nearby people
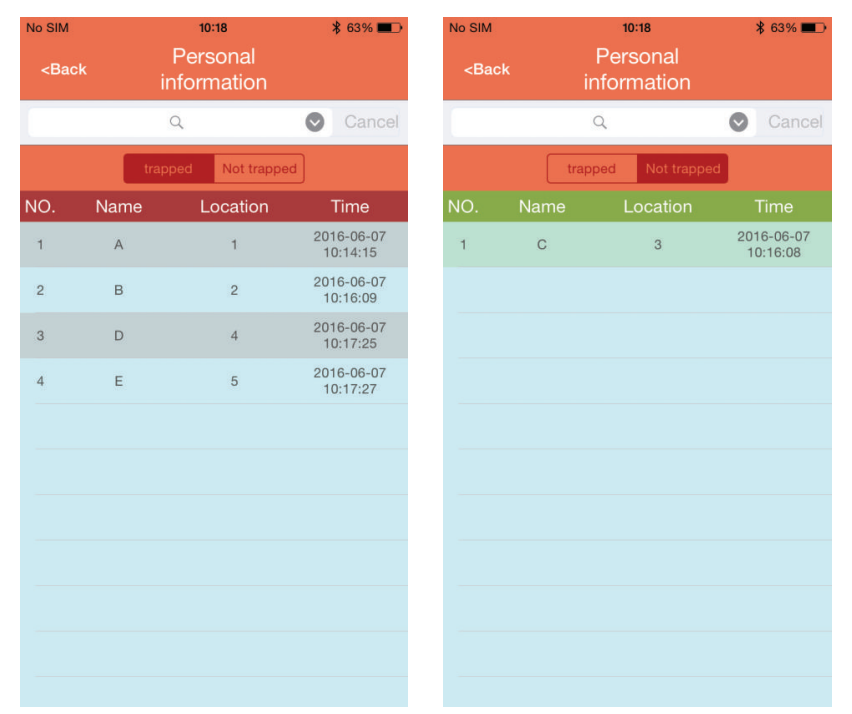

(c) Database on F's smartphone

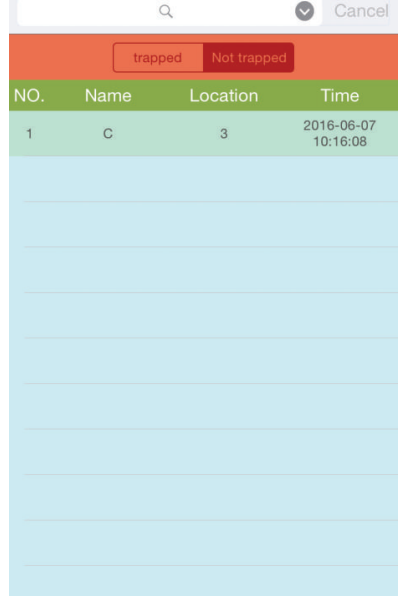

(d) F's nearby people

FIGURE 9: Results of moving node experiment.

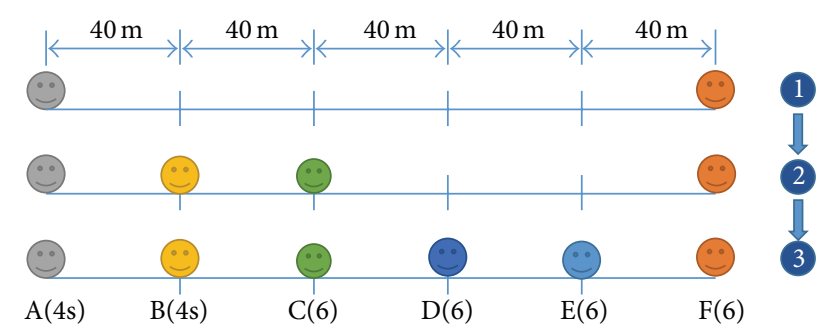

FIgURE 10: Dense node experiment diagram.

For the third step, D and E are added between C and F; the information on F's smartphone is shown in Figure 11(b); it can be seen that although only $\mathrm{E}$ is near to $\mathrm{F}$, all their information can be shared.

From this experiment, it can be concluded that, with the quality of E-Explorer increasing, the information can be transmitted more widely. So, a smartphone equipped with EExplorer can be used as a node in the information transmission network. The communication diagram is shown in Figure 12; each point is a node with E-Explorer, and a communication line can be built between them if the distance between two nodes is within the maximum communication distance; consequently, these two nodes can be connected successfully. As long as a sufficient number of nodes exist in the disaster zone, the communication between every two nodes can be built, and the help information can be shared. E-Explorer can build a temporary communication network system in the earthquake region, to overcome the communication difficulty under no external network connections. As Figure 12 shows, the help information of the trapped survivor A can be passed to relief worker $B$ through several nodes; of course, the presented transmission line between $\mathrm{A}$ and $\mathrm{B}$ is not the only one.
From the validation experiments, it can be concluded that E-Explorer is an information storage and delivery platform. During the rescue, the rescued persons can transfer a large amount of help information of the survivors to the outside, which is helpful to take rescue measures quickly with the assistance of the obtained information about trapped condition and location.

\section{Quick Seismic Damage Investigation Based on E-Explorer}

4.1. Traditional Seismic Damage Investigation Method. Disaster information acquired in a short time after an earthquake is the key to ensure the timeliness and accuracy of the intensity map and provide scientific guidance for rescue. Field investigation is the most common traditional method. As Figure 13 shows, experts need to gain a mount of seismic damage data in survey points and then go back to headquarters every day to summarize and analyze the damage information. The assessment of intensity relies on expert experience. The investigated building type, the damage level choice, and the difference between country and city-all these factors may lead to a different result.

Under this working pattern, the output of seismic intensity map needs much more time, especially in a serious earthquake. For example, after the earthquake in Wenchuan in 2008 occurred, experts were mobilized by China Earthquake Administration to investigate in many provinces. The final 8.0 seismic intensity map was obtained based on more than 50 square kilometers and more than 4150 survey points. It took more than 20 days to complete the intensity map of Wenchuan earthquake. The investigation speed was relatively low. 


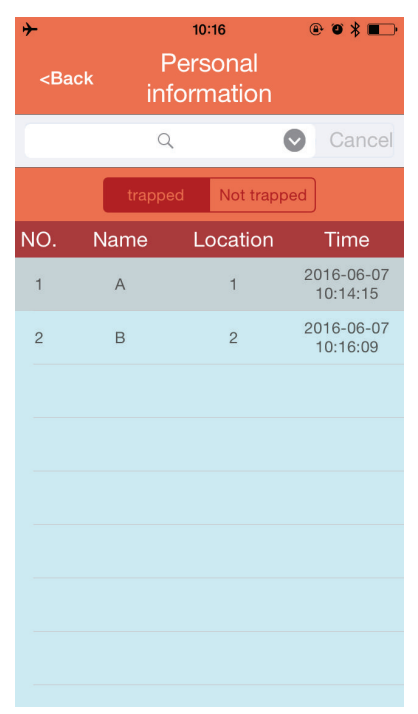

(a) C's information in step 2

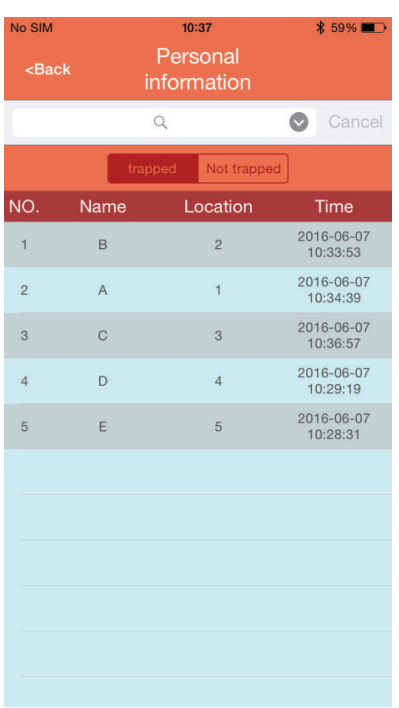

(b) F's information in step 3

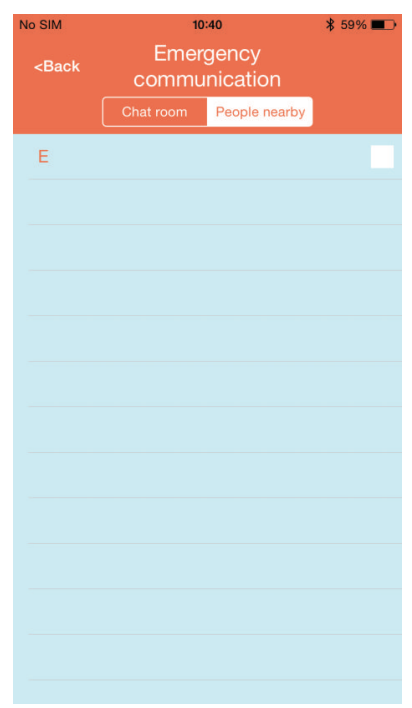

(c) F's nearby people in step 3

FIGURE 11: Results of dense node experiment.

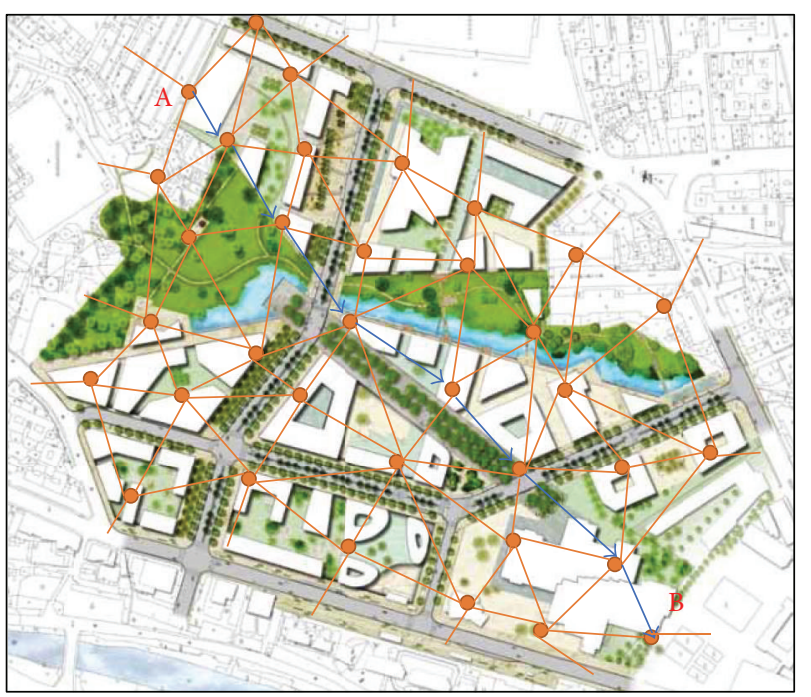

FIGURE 12: Information transmission line schematic.

\subsection{Quick Seismic Damage Investigation Method Using E-Explorer}

4.2.1. Principle of the Method. Immediate knowledge of the precise location and degree of damage saves time and saves lives. Such information is critical to disaster relief teams and public safety personnel to protect lives and reduce property loss. Previous traditional methods are ineffective and timewasting. Therefore, a quick seismic investigation method using E-Explorer is proposed. The screenshot of seismic survey point with two purposes on E-Explorer is shown in Figure 14. The principle of this smartphone-based method is shown in Figure 15.

As Figure 15 shows, the smartphone-based investigation method employs E-Explorer to take damage photos, fill in questionnaire, and collect position information and then upload the information to the data sharing website, and the information uploaded will be presented on the map. Last, the information is analyzed and summarized online to realize quick seismic damage assessment. Both professional staff and residents could collect information via smartphones; residents could report and receive information via the website to care about the situation of their own position, and communities could share information simultaneously to respond to a crisis of any damage magnitude.

4.2.2. Questionnaire Investigation. Seismic intensity indicates the seismic damage level and is evaluated by the consequences after the earthquake based on intensity scale. Intensity map expresses the damage level and disaster distribution intuitively, which is a basis for emergency relief works, such as the rapid deployment of rescue workers and materials. So, it is important to obtain the intensity map as soon as possible.

After the earthquake occurred, every person including seismic workers, volunteers, and residents can use E-Explorer to fill in the questionnaire according to the macroscopic phenomenon, which just takes a few minutes. Then, the result of the questionnaire with the location can be uploaded to the website. If there is no network in the investigation spot, the collected data can be stored and shared by using the emergency communication. Once one person's network is available, all information can be uploaded to the website. With this questionnaire, every smartphone with E-Explorer can help experts to accomplish intensity evaluation more efficiently.

The questionnaire is mainly based on the Chinese Seismic Intensity Scale (2008) [33] and takes macroscopic signs of seismic intensity as survey unit: feelings of people, reactions of objects, and conditions of building damage and earth's surface. The long-term practice shows that these macroscopic 


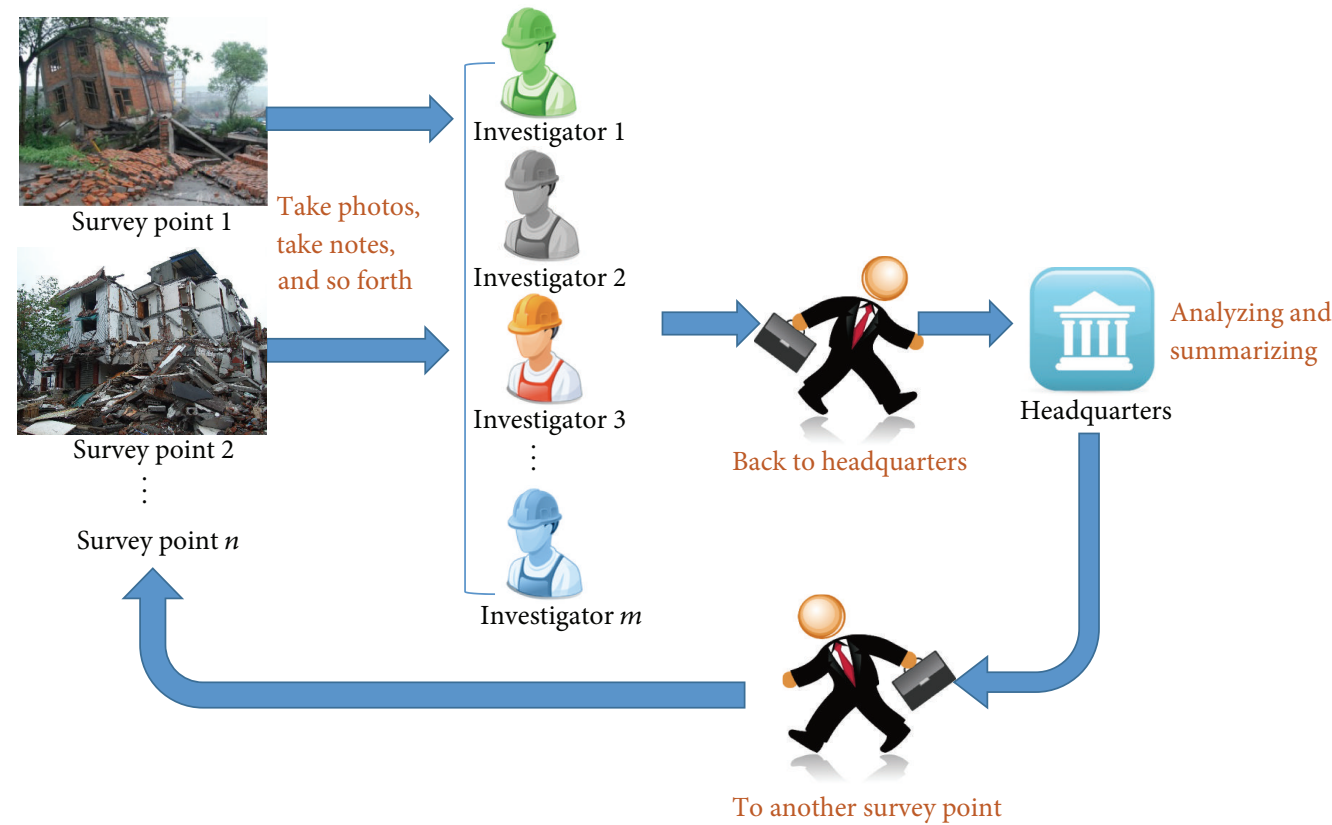

FIGURE 13: Traditional seismic damage investigation method.

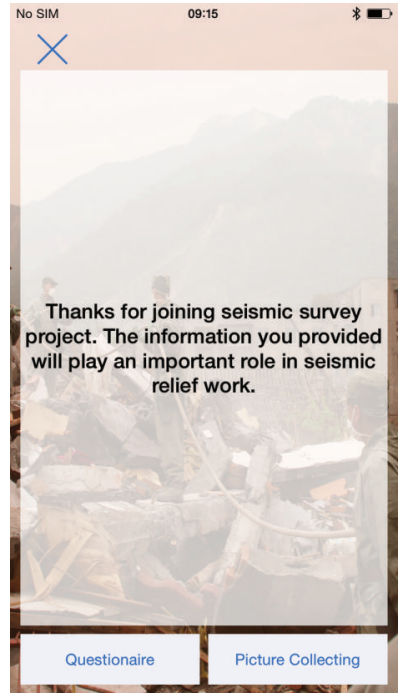

FIGURE 14: Screenshot of seismic survey.

signs are an effective criterion for seismic intensity evaluation, especially in China which has sparseness in seismic observation stations.

The questionnaire has seven questions which can be easily done by nonexperts (e.g., residents) who have not received professional training. Only with the strength of the masses at the real earthquake site can we get as much valuable and effective information as possible to carry out earthquake relief work in time. Figure 16 shows two questions of the questionnaire. Residents can choose the corresponding answer according to the actual situation. Then, the answers will be saved and uploaded to the website. The intensity value cannot be obtained directly according to the questionnaire on
E-Explorer, but the basic macrophenomenon information will be a reference for the damage assessment.

All questions and options are given in Table 4.

4.2.3. Pictures Collection. The answers may be different between nonexperts and experts, which may falsify the damage evaluation dramatically. Therefore, it was decided to focus on smartphones' cameras and consider the questionnaire as a supplement of the pictures. Residents can serve as "moving sensors" that can collect data information following the directions given by E-Explorer without any evaluation [27]. Pictures are the most important proof to assess the damage level. The screenshot of the pictures collection is shown in Figure 17.

\subsection{Intensity Evaluation}

4.3.1. Houses Type. The damage levels of different house types are obviously different, so house type is an important parameter for intensity evaluation. House type is classified into three categories according to the Chinese Seismic Intensity Scale (2008) [33].

Type A. This type is timber frame and antique house constructed by soil, stone, and brick.

Type B. This type is monolayer or multilayer brick masonry buildings without seismic fortification.

Type C. This type is monolayer or multilayer brick masonry buildings designed according to the 7-degree seismic fortification.

4.3.2. Definition of Quantifier. The descriptions for seismic influence and damage phenomena are macroscopic in 


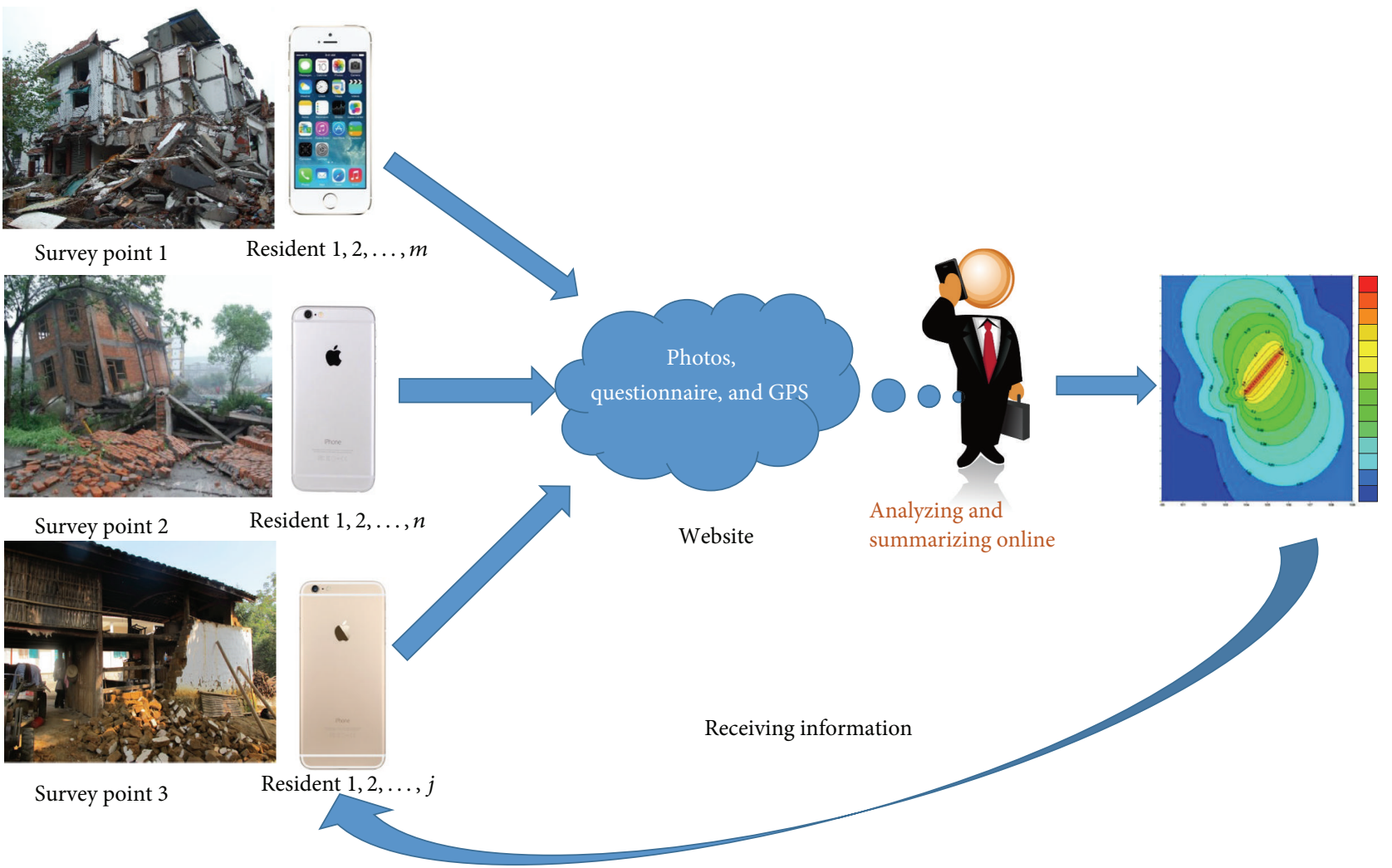

FIGURE 15: Flow chart of seismic damage investigation using smartphone.

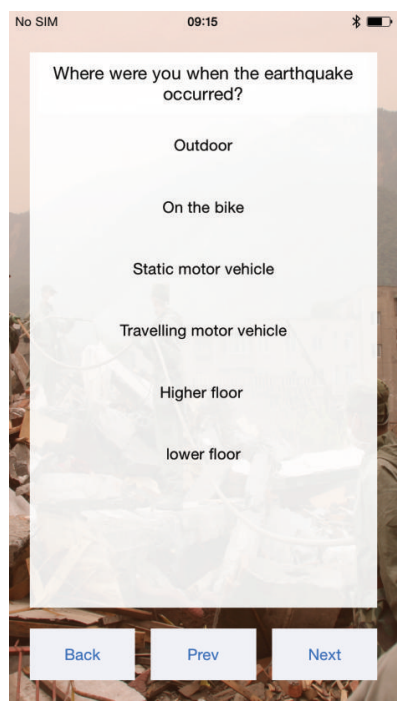

(a) Question 1

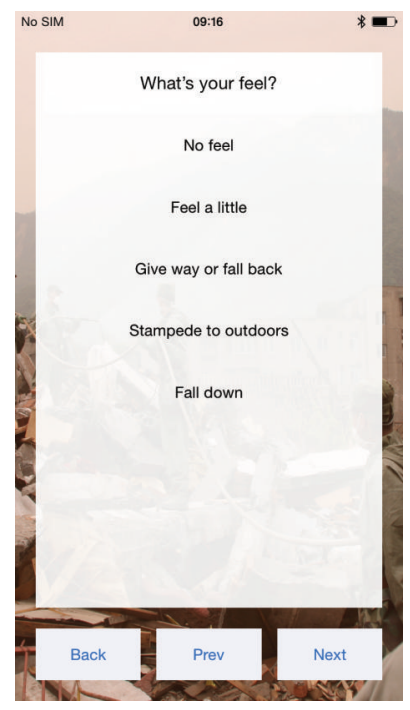

(b) Question 2

FIGURE 16: Screenshots of the questionnaire.

the intensity scale and are expressed by fuzzy words. Their range is specified as follows:
(a) Several: 0-10\%.
(b) Minority: $10 \%-45 \%$.
(c) Majority: 40\%-70\%.

(d) Great majority: 60\%-90\%.

(e) Vast majority: $80 \%-100 \%$.

4.3.3. Earthquake Damage Index. Earthquake damage index grades the damage levels of houses. The damage index not only can evaluate the damage of a single house conveniently, 
TABLE 4: All questions and options on questionnaire.

\begin{tabular}{|c|c|}
\hline Question & Options \\
\hline \multirow{6}{*}{$\begin{array}{l}\text { Where were you when the } \\
\text { earthquake occurred? }\end{array}$} & (a) Outdoor \\
\hline & (b) On the bike \\
\hline & (d) Static motor vehicle \\
\hline & (e) Travelling motor vehicle \\
\hline & (c) Higher floor \\
\hline & (d) lower floor \\
\hline \multirow{5}{*}{ What's your feel? } & (a) No feel \\
\hline & (b) Feel a little \\
\hline & (c) Give way or fall back \\
\hline & (d) Stampede to outdoors \\
\hline & (e) Fall down \\
\hline \multirow{4}{*}{$\begin{array}{l}\text { What's the reaction of } \\
\text { hanging objects? }\end{array}$} & (a) Slight shaking \\
\hline & (b) Obvious shaking \\
\hline & (c) Substantially shaking \\
\hline & (d) Objects dropped \\
\hline \multirow{4}{*}{$\begin{array}{l}\text { What's the reaction of the } \\
\text { implements? }\end{array}$} & (a) Slight shaking \\
\hline & (b) Obvious shaking \\
\hline & $\begin{array}{l}\text { (c) Implements in higher place } \\
\text { overturned }\end{array}$ \\
\hline & $\begin{array}{l}\text { (d) Unstable implements are } \\
\text { overturned }\end{array}$ \\
\hline \multirow{4}{*}{$\begin{array}{l}\text { What's the condition of } \\
\text { the surface of the earth? }\end{array}$} & (a) Cracks appears on soft soil \\
\hline & (b) Cracks appears on dry ground \\
\hline & $\begin{array}{l}\text { (c) Large surface fractures, landslide } \\
\text { occurs }\end{array}$ \\
\hline & (d) Mountains fall and the earth splits \\
\hline \multirow{5}{*}{ How about your house? } & (a) Largely intact \\
\hline & $\begin{array}{l}\text { (b) Slight damage (several obvious } \\
\text { cracks) }\end{array}$ \\
\hline & $\begin{array}{l}\text { (c) Moderate damage (more obvious } \\
\text { cracks) }\end{array}$ \\
\hline & $\begin{array}{l}\text { (d) serious damage (collapsed } \\
\text { partially) }\end{array}$ \\
\hline & (e) Destruction (collapsed totally) \\
\hline \multirow{4}{*}{$\begin{array}{l}\text { What's the type of your } \\
\text { house? }\end{array}$} & $\begin{array}{l}\text { (a) Old houses built by wood, soil, } \\
\text { stone and brick }\end{array}$ \\
\hline & $\begin{array}{l}\text { (b) Monolayer or multilayer brick } \\
\text { masonry building without the seismic } \\
\text { fortified }\end{array}$ \\
\hline & $\begin{array}{l}\text { (c) Monolayer or multilayer brick } \\
\text { masonry building design according to } \\
7 \text { degree earthquake }\end{array}$ \\
\hline & (d) Other \\
\hline
\end{tabular}

but also can evaluate the damage of one survey point (e.g., take a village as a unit) based on statistics. It is a refining and quantitative expression for damage level. Damage index ranges from 0.00 (no damage) to 1.00 (completely destroyed).

The gradation of damage is divided into five levels: largely intact level, minor damage level, moderate damage level,

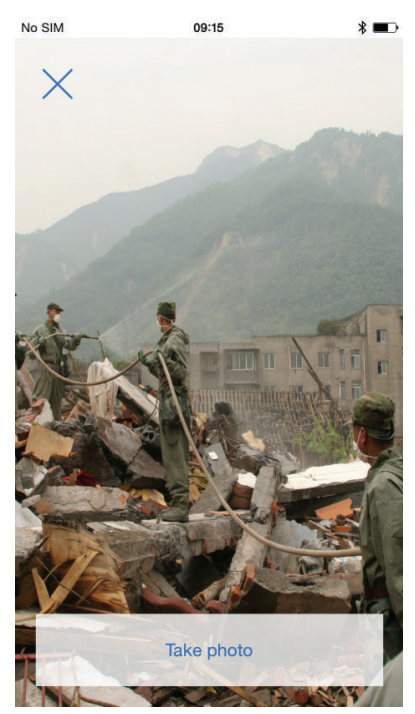

FIGURE 17: Screenshot of picture collection.

serious damage level, and destruction level. Their descriptions and corresponding damage index are shown in Table 5.

The mean damage index of one house type in one survey point is calculated according to

$$
D_{j}=\sum_{i=1}^{5} d_{i, j} \lambda_{i, j},
$$

where $D_{j}$ is the mean damage index of house type $j, d_{i, j}$ is the damage index of house type $j$ in $i$ th damage level, and $\lambda_{i, j}$ is the ratio of the damage level $i$ of type $j$ and is expressed as

$$
\lambda_{i, j}=\frac{S_{i, j}}{\sum_{i=1}^{5} S_{i, j}},
$$

where $S_{i, j}$ is the house area or quantity of type $j$, in $i$ th damage level.

Mean damage index $D$ in one survey point can be obtained by solving the weighted average of $D_{j}$ according to the area of each house type. And it is calculated as

$$
D=\sum_{j} D_{j} \lambda_{j}
$$

where $\lambda_{j}$ is the ratio between house type $j$ and total houses and is expressed as

$$
\lambda_{j}=\frac{S_{j}}{S}
$$

where $S_{j}$ is the house area or quantity of type $j$ and $S$ is the total house area or quantity in a survey point.

The intensity evaluation progress based on E-Explorer is shown in Figure 18.

As Figure 18 shows, in one survey point, the damage pictures and questionnaire can be uploaded to the website by residents; the professionals can evaluate the damage index based on the pictures and then obtain the mean damage index. 
TABLE 5: Quantization table of earthquake damage level.

Earthquake damage level Earthquake damage index

Level 1: largely intact; bearing and nonbearing component in good condition or several nonbearing components have minor damage and can continue to be used without repair.

Level 2: minor damage; several bearing components have visible cracks; nonbearing components have obvious cracks; several nonbearing components suffer severe damage and can continue to be used after general repair.

Level 3: moderate damage; majority of bearing components have invisible cracks; minority of bearing components have obvious cracks; several nonbearing components suffer severe damage and can continue to be used after general repair.

Level 4: serious damage; majority of bearing components suffer severe damage; nonbearing components exhibit local collapse; it is hard to repair the house.

Level 5: destruction; majority of bearing components suffer severe damage; it is impossible to repair the house.

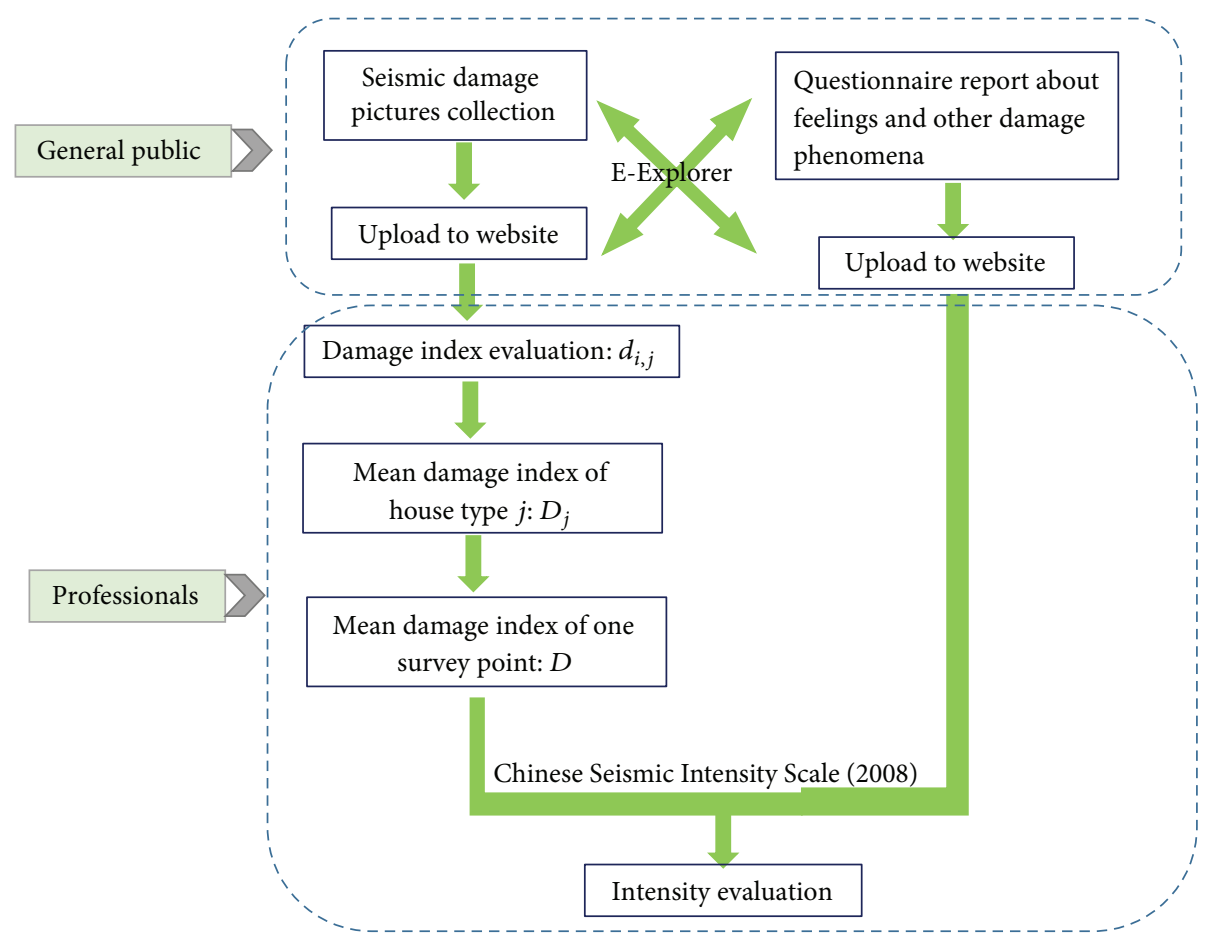

FIGURE 18: Intensity evaluation progress based on E-Explorer.

The intensity can be judged according to Table 6 by using the damage index and questionnaire answers. Intensity I to intensity $\mathrm{V}$ is judged mainly based on people's feelings and is omitted in the paper. Table 6 shows the intensity macroscopic description and corresponding damage index according to Chinese Seismic Intensity Scale (2008).

In conclusion, according to Chinese Seismic Intensity Scale (2008), the following steps are essential for quick intensity evaluation. First, motivate the residents to take photos and fill in the questionnaire on E-Explorer by using their smartphones and then upload the information to the website. Professionals check and assess the intensity from epicenter to outside according to the map on the website. Take natural village as an investigation element in the countryside, and take blocks as an investigation element in the city. Last, determine the house type and mean damage index to assess intensity in seismic area. This method makes residents play a significant role in collaborating with experts to obtain damage information in a short time.

\section{The Establishment of the Website}

In order to build an emergency response system, a website is built to manage the big data uploaded from E-Explorer. The URL is http://www.e-explorer.cn/, which is shown in Figure 19.

There are two purposes of the website. The first is to release the name, location, and other information of the trapped people, which can be visually displayed on the map. 
TABLE 6: Macroscopic description of intensity level and corresponding damage index.

\begin{tabular}{|c|c|c|c|}
\hline Intensity & House type & Macroscopic description & $\begin{array}{l}\text { Mean damage } \\
\text { index }\end{array}$ \\
\hline \multirow{3}{*}{ VI } & A & $\begin{array}{l}\text { Minority in moderate damage level, majority in minor } \\
\text { damage level and/or largely intact level }\end{array}$ & \multirow[t]{2}{*}{$0.00-0.11$} \\
\hline & $\mathrm{B}$ & $\begin{array}{l}\text { Several in moderate damage level, minority in minor } \\
\text { damage level, majority in largely intact level }\end{array}$ & \\
\hline & $\mathrm{C}$ & $\begin{array}{l}\text { Several in minor damage level, majority in largely intact } \\
\text { level }\end{array}$ & $0.00-0.08$ \\
\hline \multirow[t]{3}{*}{ VII } & A & $\begin{array}{c}\text { Minority in serious damage level and/or destruction } \\
\text { level, majority in moderate damage level and/or minor } \\
\text { damage level }\end{array}$ & \multirow[t]{2}{*}{$0.09-0.31$} \\
\hline & $\mathrm{B}$ & $\begin{array}{l}\text { Minority in moderate damage level, majority in minor } \\
\text { damage level and/or largely intact level }\end{array}$ & \\
\hline & $\mathrm{C}$ & $\begin{array}{c}\text { Minority in moderate damage level and/or minor } \\
\text { damage level, majority in largely intact level }\end{array}$ & $0.07-0.22$ \\
\hline \multirow{3}{*}{ VIII } & A & $\begin{array}{l}\text { Minority in destruction level, majority in serious } \\
\text { damage level and/or moderate damage level }\end{array}$ & \multirow[t]{2}{*}{$0.29-0.51$} \\
\hline & $\mathrm{B}$ & $\begin{array}{c}\text { Several in destruction level, minority in serious damage } \\
\text { level, majority in moderate damage level and/or minor } \\
\text { damage level }\end{array}$ & \\
\hline & $\mathrm{C}$ & $\begin{array}{c}\text { Minority in serious damage level and/or moderate } \\
\text { damage level, majority in minor damage level }\end{array}$ & $0.20-0.40$ \\
\hline \multirow{3}{*}{ IX } & A & $\begin{array}{c}\text { Majority in serious damage level and/or destruction } \\
\text { level }\end{array}$ & \multirow[t]{2}{*}{$0.49-0.71$} \\
\hline & $\mathrm{B}$ & $\begin{array}{l}\text { Minority in destruction level, majority in serious } \\
\text { damage level and/or moderate damage level }\end{array}$ & \\
\hline & $\mathrm{C}$ & $\begin{array}{c}\text { Minority in destruction level and/or serious damage } \\
\text { level, majority in moderate damage level and/or minor } \\
\text { damage level }\end{array}$ & $0.38-0.60$ \\
\hline \multirow{3}{*}{$\mathrm{X}$} & A & Vast majority in destruction level & \multirow{2}{*}{$0.69-0.91$} \\
\hline & $\mathrm{B}$ & Great majority in destruction level & \\
\hline & $\mathrm{C}$ & $\begin{array}{l}\text { Majority in destruction level and/or serious damage } \\
\text { level }\end{array}$ & $0.58-0.80$ \\
\hline \multirow[t]{2}{*}{$\mathrm{XI}$} & $\begin{array}{l}\text { A } \\
\text { B }\end{array}$ & Vast majority in destruction level & $0.89-1.00$ \\
\hline & $\mathrm{C}$ & & $0.78-1.00$ \\
\hline \multirow{3}{*}{ XII } & $\mathrm{A}$ & & \multirow{3}{*}{1.00} \\
\hline & B & Almost all in complete destruction level & \\
\hline & $\mathrm{C}$ & & \\
\hline
\end{tabular}

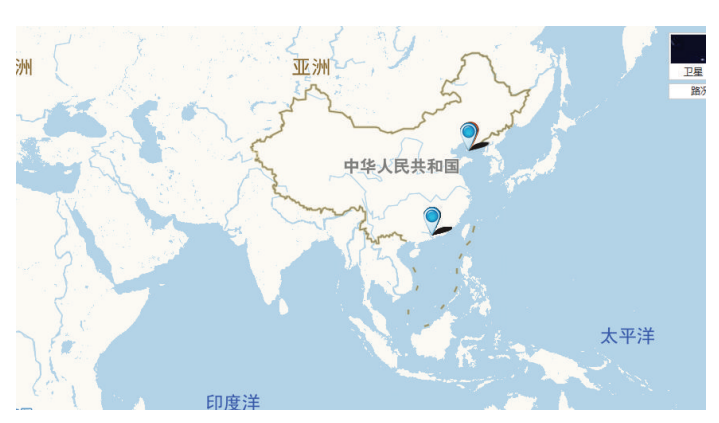

(a) Main page on the website

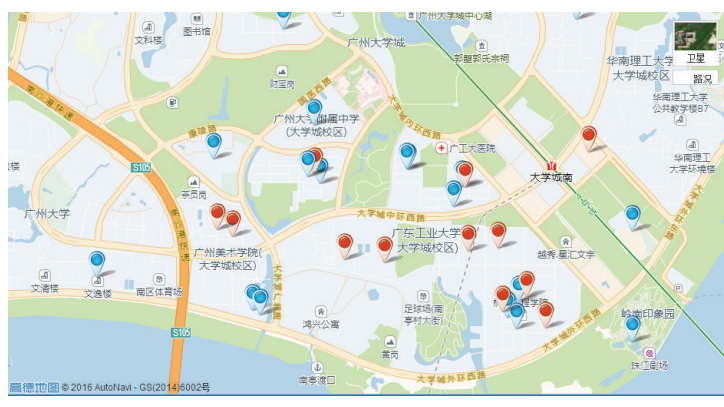

(b) People on the map

Figure 19: The website. 
Figure 19(a) shows the main map of the website, and Figure 19(b) shows the local information with marks, which are the submitted information by users. The blue mark refers to people not trapped, and the red mark stands for people trapped. The detailed information can be shown by clicking the mark. According to the data on the website, officers can obtain casualties statistics quickly, and the information on the website can also provide scientific guidance for rescue.

The second purpose is to collect the damage information from smartphones, reduce the field investigation time, and realize the quick seismic damage evaluation by checking the information on the website.

\section{Conclusions}

In this paper, an application, E-Explorer, and a website are developed on iOS operating system to realize emergency communication and quick seismic damage investigation. EExplorer is made up of two basic modules. The emergency communication module makes the information transmission possible without external network connections, which can provide important information to others for personal survival, enhance the possibility of communication, and increase the chances for rescue. Three experiments validated the connection, connection distance, and information transmission of emergency communication. The damage investigation module provides a quick investigation method for seismic damage with the assistance of picture collection, questionnaire, and data uploading. Last, a website, http://www.eexplorer.cn/, is built to gather big data of the personal information and damage information, and then more scientific responses can be carried out after analyzing the uploaded information. So, this technique promises to be an efficient tool for postdisaster relief. A resident with a smartphone is a potential rescuer to help trapped people, a potential investigator of emergency information, a potential reporter to transmit information, and a potential recipient of information that might prove lifesaving. The application will be developed and discussed on other operating systems in our future work, and the adaptability of the seismic intensity assessment in other regions will be involved in the next stage.

\section{Competing Interests}

The authors declare that there are no competing interests regarding the publication of this paper.

\section{Acknowledgments}

This research was financially supported by the National Natural Science Foundation of China (51278085, 51479031, and 51161120359), the National Basic Research Program of China (2011CB013705), Program for Liaoning Excellent Talents in University (LJQ2015028), and the Fundamental Research Funds for the Central Universities (DUT15ZD117).

\section{References}

[1] M. Domaneschi and L. Martinelli, "Earthquake-resiliencebased control solutions for the extended benchmark cablestayed bridge," Journal of Structural Engineering, Article ID C4015009, 2015.

[2] C. W. Zobel and L. Khansa, "Characterizing multi-event disaster resilience," Computers and Operations Research, vol. 42, pp. 8394, 2014.

[3] Y. Kuwata and S. Takada, "Rescue ability for earthquake casualty during the 1995 Kobe Earthquake," Departmental Bulletin Paper, pp. 215-220, 2000.

[4] G. P. Cimellaro, A. M. Reinhorn, and M. Bruneau, "Framework for analytical quantification of disaster resilience," Engineering Structures, vol. 32, no. 11, pp. 3639-3649, 2010.

[5] G. P. Cimellaro, A. M. Reinhorn, and M. Bruneau, "Seismic resilience of a hospital system," Structure and Infrastructure Engineering, vol. 6, no. 1-2, pp. 127-144, 2010.

[6] M. Pelling, The Vulnerability of Cities: Natural Disasters and Social Resilience, Earthscan, 2012.

[7] S. L. Cutter, L. Barnes, M. Berry et al., "A place-based model for understanding community resilience to natural disasters," Global Environmental Change, vol. 18, no. 4, pp. 598-606, 2008.

[8] B. Maguire and H. Patrick, "Disasters and communities: understanding social resilience," Australian Journal of Emergency Management, vol. 22, no. 2, pp. 16-20, 2004.

[9] M. G. Kweit and R. W. Kweit, "Citizen participation and citizen evaluation in disaster recovery," The American Review of Public Administration, vol. 34, no. 4, pp. 354-373, 2004.

[10] Y. Shu, M. Xu, and Y. Liu, "Self-help and mutual rescue-the relief work in serious earthquake," Journal of Hebei Institute of Technology: Social Science Edition, vol. 3, no. 3, pp. 33-35, 2003 (Chinese).

[11] M. Schoch-Spana, C. Franco, J. B. Nuzzo, and C. Usenza, "Community engagement: leadership tool for catastrophic health events," Biosecurity and Bioterrorism, vol. 5, no. 1, pp. 8-25, 2007.

[12] L. K. Comfort, Shared Risk: Complex Systems in Seismic Response, Emerald Group Publishing, Somerville, Mass, USA, 1999.

[13] L. K. Comfort and N. Kapucu, "Inter-organizational coordination in extreme events: the world trade center attack," Natural Hazards, vol. 39, pp. 309-327, 2001.

[14] S. L. Lau and K. David, "Movement recognition using the accelerometer in smartphones," in Proceedings of the IEEE Future Network and Mobile Summit, pp. 1-9, Florence, Italy, June 2010.

[15] H. Ketabdar and T. Polzehl, "Fall and emergency detection with mobile phones," in Proceedings of the 11th International ACM SIGACCESS Conference on Computers and Accessibility (ASSETS '09), pp. 241-242, Pittsburgh, Pa, USA, October 2009.

[16] M. Mladenov and M. Mock, "A step counter service for Javaenabled devices using a built-in accelerometer," in Proceedings of the ACM 1st International Workshop on Context-Aware Middleware and Services: Affiliated with the 4th International Conference on Communication System Software and Middleware (COMSWARE '09), pp. 1-5, Dublin, Ireland, June 2009.

[17] J. Reilly, S. Dashti, M. Ervasti, J. D. Bray, S. D. Glaser, and A. M. Bayen, "Mobile phones as seismologic sensors: automating data extraction for the ishake system," IEEE Transactions on Automation Science and Engineering, vol. 10, no. 2, pp. 242-251, 2013. 
[18] Y. Yu, X. Zhao, and J. Ou, "A new idea: mobile structural health monitoring using Smart phones," in Proceedings of the $3 \mathrm{rd}$ International Conference on Intelligent Control and Information Processing (ICICIP '12), pp. 714-716, Dalian, China, July 2012.

[19] X. Zhao, R. Han, Y. Ding et al., "Portable and convenient cable force measurement using smartphone," Journal of Civil Structural Health Monitoring, vol. 5, no. 4, pp. 481-491, 2015.

[20] Y. Yu, R. Han, X. Zhao et al., "Initial validation of mobilestructural health monitoring method using smartphones," International Journal of Distributed Sensor Networks, vol. 2015, Article ID 274391, 14 pages, 2015.

[21] X. Zhao, D. Peng, W. Hu et al., "Quick seismic intensity map investigation and evaluation based on cloud monitoring method using smart mobile phone," in Proceedings of the in SPIE Smart Structures and Materials + Nondestructive Evaluation and Health Monitoring, vol. 9437 of Proceedings of SPIE, p. 94372, The International Society for Optics and Photonics, San Diego, Calif, USA, March 2015.

[22] G. Morgenthal and H. Höpfner, "The application of smartphones to measuring transient structural displacements," Journal of Civil Structural Health Monitoring, vol. 2, no. 3-4, pp. 149161, 2012.

[23] H. Höpfner, G. Morgenthal, M. Schirmer, M. Naujoks, and C. Halang, "On measuring mechanical oscillations using smartphone sensors: possibilities and limitation," ACM SIGMOBILE Mobile Computing and Communications Review, vol. 17, no. 4, pp. 29-41, 2013.

[24] M. Feng, Y. Fukuda, M. Mizuta, and E. Ozer, "Citizen sensors for SHM: use of accelerometer data from smartphones," Sensors, vol. 15, no. 2, pp. 2980-2998, 2015.

[25] E. Ozer, M. Q. Feng, and D. Feng, "Citizen sensors for SHM: towards a crowdsourcing platform," Sensors, vol. 15, no. 6, pp. 14591-14614, 2015.

[26] M. Fujiu, M. Ohara, and K. Meguro, "Development of remote building damage assessment system during large-scale earthquake disaster," in Proceedings of the 15th World Conference on Earthquake Engineering (WCEE '12), pp. 24-28, Lisbon, Portugal, September 2012.

[27] V. Arcidiacono and G. P. Cimellaro, "Damage report with smartphones during Emilia earthquake, 2012," in Proceedings of the 4th International Conference on Computational Methods in Structural Dynamics and Earthquake Engineering (COMPDYN '13), pp. 517-526, Kos Island, Greece, June 2013.

[28] G. Scura, V. Arcidiacono, G. P. Cimellaro, C. Renschler, and A. M. Reinhorn, "Integrated damage assessment communication system using smartphone network during 2012 Emilia earthquake," in Proceedings of the Vienna Congress on Recent Advances in Earthquake Engineering and Structural Dynamics \& 13. D-A-CH Tagung (VEESD '13), Vienna, Austria, August 2013.

[29] G. P. Cimellaro, G. Scura, C. S. Renschler, A. M. Reinhorn, and H. U. Kim, "Rapid building damage assessment system using mobile phone technology," Earthquake Engineering and Engineering Vibration, vol. 13, no. 3, pp. 519-533, 2014.

[30] http://nshipster.com/multipeer-connectivity/.

[31] https://www.apple.com/cn/iphone-6s/specs/.

[32] https://zh.wikipedia.org/wiki/IEEE_802.11.

[33] GB/T, "Chinese seismic intensity scales," GB/T 17742-2008, 2008. 

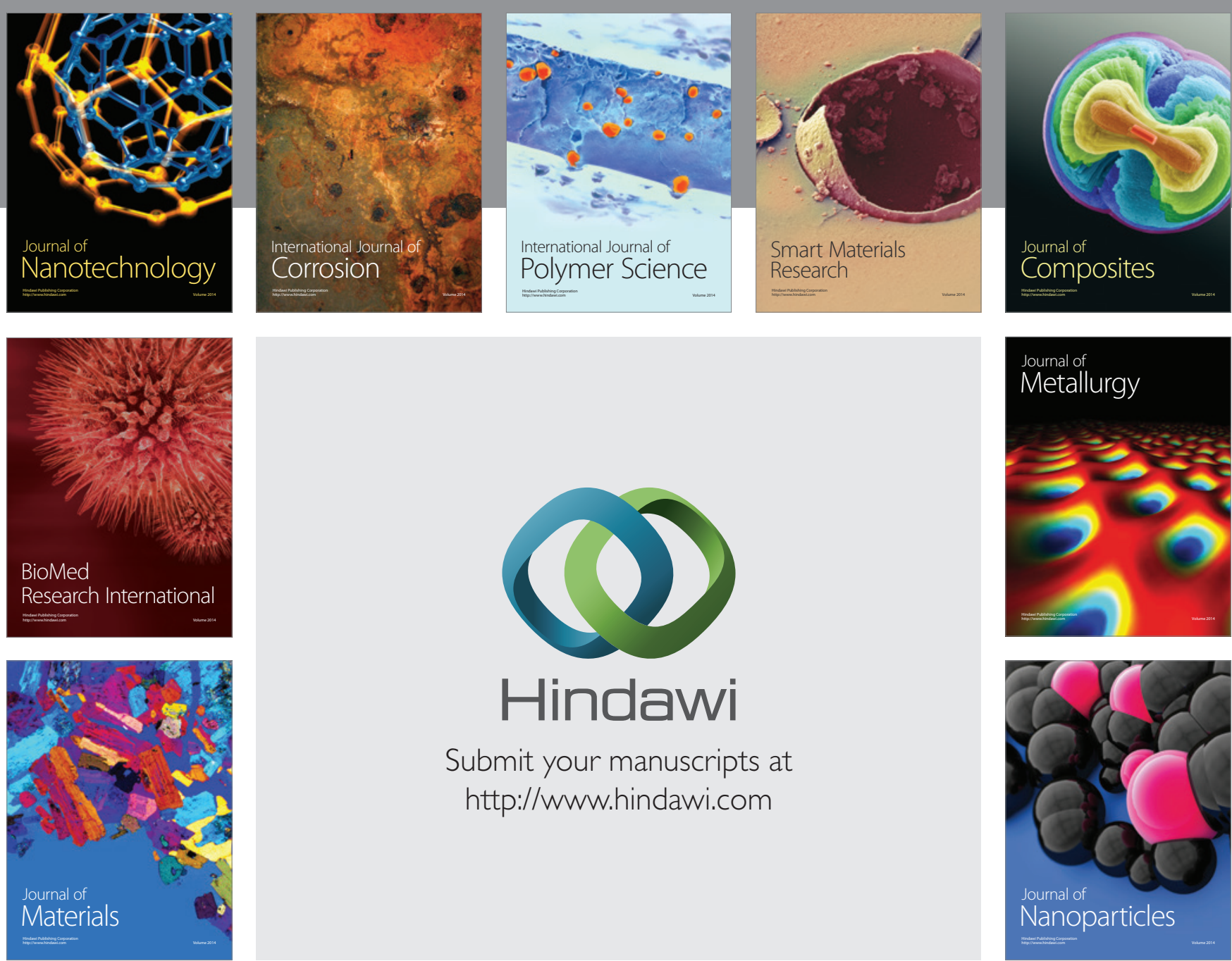

\section{Hindawi}

Submit your manuscripts at

http://www.hindawi.com

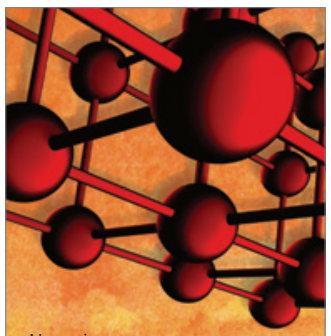

Materials Science and Engineering
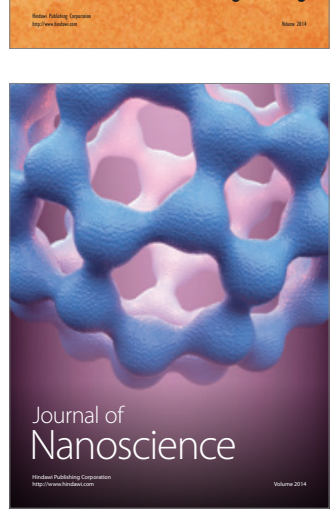
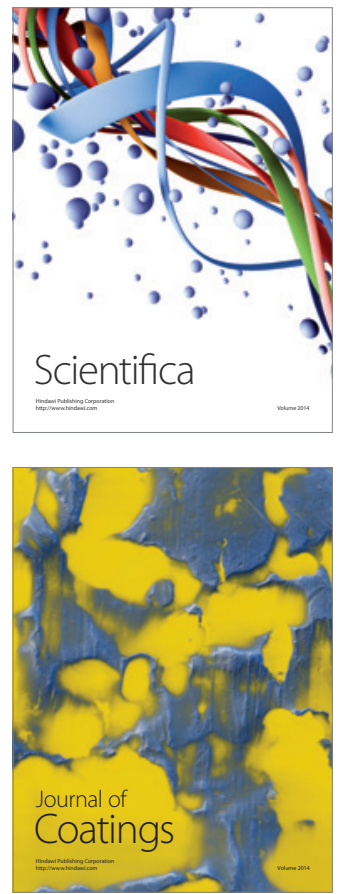
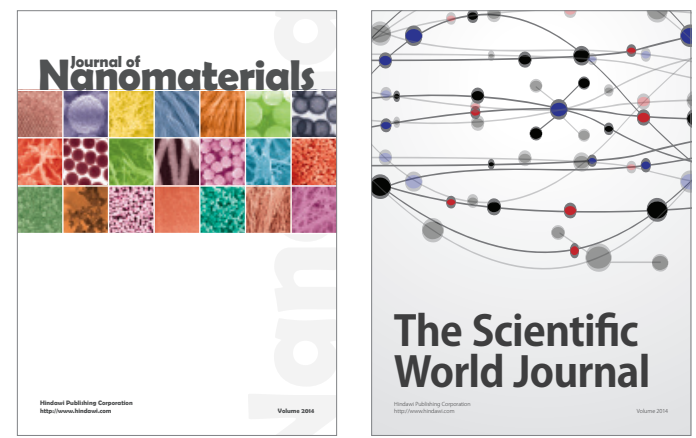

The Scientific World Journal
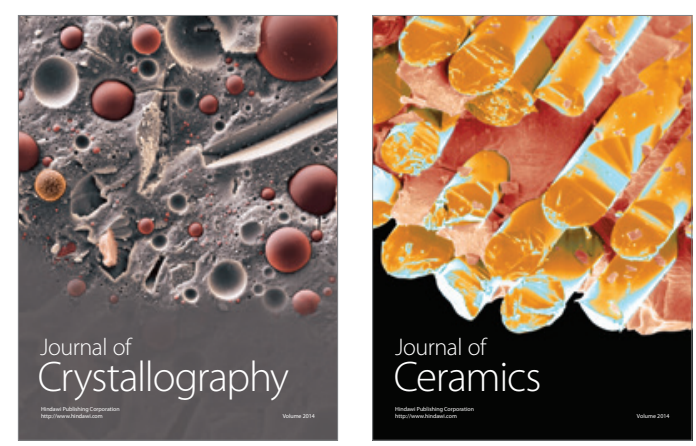
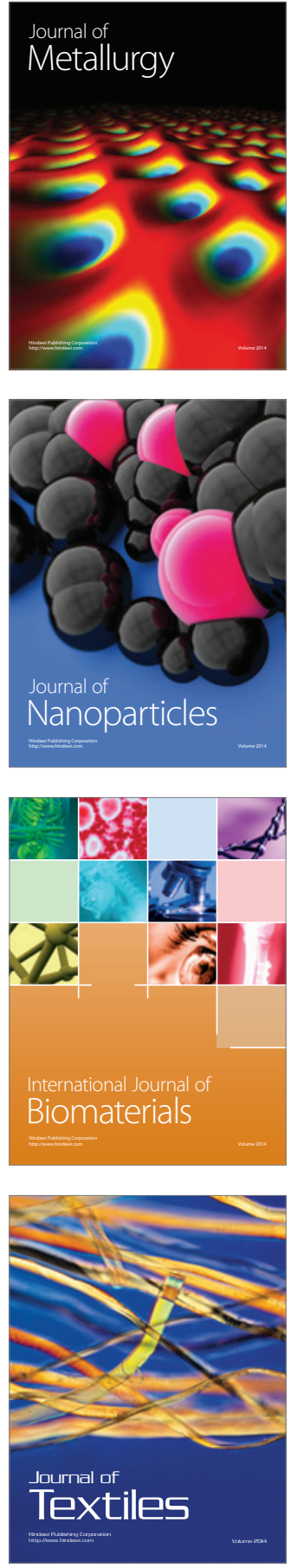